\title{
Milène Moris-Stefkovic, Vision et poésie dans l'œuvre romanesque de Sylvie Germain
}

\section{Elisa Bricco}

\section{Q OpenEdition}

1 Journals

\section{Edizione digitale}

URL: http://journals.openedition.org/studifrancesi/4487

DOI: $10.4000 /$ studifrancesi. 4487

ISSN: 2421-5856

\section{Editore}

Rosenberg \& Sellier

\section{Edizione cartacea}

Data di pubblicazione: 1 settembre 2016

Paginazione: 369

ISSN: 0039-2944

\section{Notizia bibliografica digitale}

Elisa Bricco, «Milène Moris-Stefkovic, Vision et poésie dans l'œuvre romanesque de Sylvie Germain », Studi Francesi [Online], 179 (LX | II) | 2016, online dal 01 septembre 2016, consultato il 18 septembre 2020. URL : http://journals.openedition.org/studifrancesi/4487 ; DOI : https://doi.org/10.4000/ studifrancesi.4487

Questo documento è stato generato automaticamente il 18 settembre 2020.

\section{(c)}

Studi Francesi è distribuita con Licenza Creative Commons Attribuzione - Non commerciale - Non opere derivate 4.0 Internazionale. 


\title{
Milène Moris-Stefkovic, Vision et poésie dans l'œuvre romanesque de Sylvie Germain
}

\author{
Elisa Bricco
}

\section{NOTIZIA}

MILÈNE MORIS-STEFKOVIC, Vision et poésie dans l'œuvre romanesque de Sylvie Germain, Paris, Champion, «Littérature de notre siècle», 2014, 311 pp.

1 L'opera di Sylvie Germain è stata oggetto di molti studi che ne riflettono la ricchezza e la grande profondità intellettuale e spirituale. Proprio quest'ultimo elemento, lo spirituale, è sempre stato evocato con una certa attenzione e cautela da parte della critica, che non può esimersi dalla constatazione della presenza di una forte dose di spiritualità cristiana e di afflato mistico, e al tempo stesso dal provare una sottile reticenza a occuparsene veramente. Il presente saggio ha questo pregio: mostrare come la forma e il contenuto concorrano a dire en creux la ricerca del divino da parte della scrittrice in ogni suo testo.

2 Lo studio ripercorre la produzione romanzesca germainiana dagli esordi nel 1985 fino al 2009, prendendo in considerazione dodici testi principali e mettendone in evidenza caratteristiche tematiche e formali per tracciare un percorso che va dalla scrittura barocca degli inizi, attraverso la frammentazione e l'essenzialità crescente nella fase mediana della produzione, sino alla condensazione e alla messa in scena «de l'effacement et de la disparition» (p. 13) nelle opere più recenti. La struttura tripartita del saggio, che ricalca le modalità di presentazione della tesi di dottorato da cui deriva, presenta una prima parte «Voir et savoir» incentrata sulla relazione tra la visione e la conoscenza; una seconda parte, "Arrêts sur image», che restringe il campo e lascia spazio all'analisi di alcuni casi emblematici in cui è illustrata la poetica del vedere nei suoi esiti diversi; infine, la terza parte opera un passaggio tematico e ontologico 
mettendo in rilievo come la visione sia affiancata da un altro senso, quello dell'udito, che permette una percezione altra della realtà e insieme una relazione diversa con essa, che è presentata spesso come inadeguata e dolorosa per i personaggi.

3 Il percorso da un canale percettivo all'altro, attraverso analisi approfondite della poetica e della scrittura di Sylvie Germain, consentono all'autrice di dimostrare che il passaggio dalla vista all'udito ricalca una sorta di ripiegamento interiore necessario, sia ai personaggi sia alla scrittrice, per continuare ad affrontare la realtà di oggi. L'assenza e la perdita progressiva di una presenza tangibile che vivono e ricercano alcuni personaggi sarebbero la dimostrazione di un loro cammino verso la ricerca della presenza del divino nel reale. Così, da un romanzo all'altro compaiono e piano piano prendono il sopravvento personaggi che si nascondono, che si fanno indistinti, che si perdono nei paesaggi che li contengono. Essi dimostrano, per la loro stessa presenza ed essenza, un atteggiamento etico, una forma diversa dello stare al mondo, assolutamente agli antipodi rispetto alle dinamiche della società dello spettacolo nella quale siamo immersi. 